\title{
A Posição do Psicanalista e Seu Desdobramento SUBJETIVO NO ESQUEMA $L^{1}$
}

\author{
Alberto Ramos Lautenchlager ${ }^{2}$
}

\section{RESUMO}

O presente trabalho pretende investigar como se dá o desdobramento subjetivo do analista nos registros lacanianos do simbólico e do imaginário. Para isso, será utilizado o esquema $\mathrm{L}$ como um shifter, isto é, um dispositivo de análise metapsicológica, afim de situar as instâncias psíquicas moi e Je do analista, de acordo, por um lado, com o plano consciente da interação concreta entre os interlocutores, que é permeado, por outro, pela a dimensão inconsciente produzida pelo uso da linguagem entre eles. É no campo do real, porém, que se encontra o vértice entre o imaginário e o simbólico, no corpo do analista, através do qual ele paga com sua pessoa, "metabolizando" os afetos transferenciais. Como desfecho, concluise que os estratos simbólicos e imaginários do analista estão intimamente imbricados e se visualizam tanto pelo silêncio do analista, quanto por suas intervenções, quando sua enunciação age com propriedades interpretativas.

PALAVRAS-CHAVE: Posição do Analista. Esquema L. Shifter. Enunciação. Sujeito Dividido.

\footnotetext{
${ }^{1}$ Trabalho final apresentado para a conclusão da Especialização no Curso de Pós-Graduação da UNESC "Psicanálise e suas intervenções nas psicopatologias atuais" (2017-2018).

2 Psicólogo. Especialista em Psicanálise e suas intervenções nas psicopatologias atuais pela UNESCUniversidade do Extremo Sul Catarinense, Criciúma-SC. Membro da "ÁGHORA PSICANALÍTICA: Estudos e transmissão". Torres-RS. E-mail: contatos.alberto@hotmail.com. Fone: (51) 984188044.ORCID: https://orcid.org/0000-0002-9784-5995
} 


\section{INTRODUÇÃO}

A posição do analista é uma expressão empregada pelo psicanalista francês Jacques Lacan nos anos 1950 e 1960 para se referir a um lugar simbólico que o analista ocupa frente ao paciente transferenciado em análise. A base para seu desenvolvimento provém, principalmente, dos escritos técnicos de Freud ([1912/1913], 1996) e de artigos publicados em $1937^{3}$. Os princípios teóricos acerca da posição do analista gravitam em torno da noção de neutralidade do agir analítico, que desloca o movimento responsivo do analista para um "não-agir positivo", na qual a ênfase recai sobre a escuta do analista e do paciente sobre seu próprio discurso (LACAN, [1951], 1998, p. 225).

Como bem lembra P. Kaufmann (1995, p. 14), Lacan deixou de lado o uso dos significantes "analisado ou paciente", em detrimento do uso das expressões analisante ou analisando, para se referir ao sujeito que abandona uma postura passiva em sua análise, como o termo paciente pode sugerir, tornando-se alguém cuja atitude é ativa no emprego da fala, fazendo-se agente de seu próprio discurso, condição que o implica - então, como o analista de sua própria análise - como responsável pela narrativa, elaboração e ressignificação de sua história. Doravante, sem adentrar nos meandros do percurso de uma análise, o presente trabalho procura debater sobre a posição ocupada pelo analista face ao analisante em análise, e como tal posição pode ser desdobrada a partir dos registros lacanianos SIR: Simbólico, Imaginário e Real.

Para isso, será utilizado o esquema $L$, do reconhecimento intersubjetivo, a fim de abordar esses três aspectos do analista de acordo com a metapsicologia lacaniana e com a noção linguística de shifter ${ }^{4}$. Na dimensão Simbólica, o analista atua sob a função de intérprete no dispositivo analítico; no plano Imaginário, o ser do analista encontra-se dividido pela linguagem e pode ser abordado através de seu eu (instância egóica ' $m o i$ ') enquanto função de síntese; no campo do Real, o analista situa-se com seu corpo, através do qual paga com seus afetos e sua pessoa (LACAN, [1958], 1998).

\footnotetext{
3 "Construções em análise" e "Análise terminável e interminável".

${ }^{4}$ Conceito proveniente do linguista R. Jakobson, próximo à noção de dêixis, do francês É. Benveniste.
} 


\section{As Posições do Analista}

Mesmo antes do início de seu Retorno a Freud, onde Lacan inicia a abordagem acerca da temática da posição do analista ao longo do "Seminário 1 - Os escritos técnicos de Freud", é possível visualizar alguns apontamentos referentes a essa noção em textos anteriores, como em "Intervenção sobre a transferência" e, mesmo, em "Para-além do 'Princípio de realidade'". Este escrito, de 1936, ao destacar que "a linguagem, antes de significar alguma coisa, significa para alguém”, já traz manifestos os pilares do que será a base do pensamento lacaniano no período de prevalência do registro Simbólico, o qual seja: a intersubjetividade como condição de constituição das subjetividades (LACAN, [1936], 1998, p. 86). Já em "Intervenção sobre a transferência", o autor delimita alguns elementos técnicos no tocante ao manejo do analista na situação transferencial, dados pelo esvaziamento da "alienação narcísica" do analista, a partir do qual este é capaz de acolher as intenções agressivas do analisante, visualizando melhor como é formada a estrutura simbólica do sujeito, e como ele estabelece e mantem suas relações objetais (LACAN, [1948], 1998, p. 220).

Iniciando a abordagem da posição do analista a partir do esquema $L$, do reconhecimento intersubjetivo, tem-se os registros Simbólico (2.1) e Imaginário (2.2). No Simbólico, o analista ocupa um lugar virtual, como uma instância terceira, que sustenta a presença do inconsciente para o analisante no setting analítico. No Imaginário, ele faz par na relação discursiva concreta e pessoal com o analisante, como seu interlocutor e "semelhante" na relação especular de 'eu a eu', ou entre o sujeito e o outro, o eixo a - a' no esquema L (LACAN, [1954-55], 1985, p. 307). Já no campo do Real (2.3), o analista participa fisgado pelos efeitos dos afetos suscitados em seu ser em meio à transferência do analisante e à sua contratransferência.

A respeito do Real, cabe uma pequena ressalva. Delimitado no período de prevalência do registro Simbólico, o foco de discussão do presente trabalho deter-seá na distinção entre os aspectos simbólico e imaginário do psicanalista, não se detendo, portanto, a quesitos do analista referentes a seu estrato real. Assim, as breves considerações acerca do aspecto real do analista dar-se-ão de acordo com as concepções presentes na transição dos anos 1950 para os anos 1960, em que Lacan passa a apontar mais frequentemente as implicações do real sobre a situação analítica. 
No registro Simbólico, a posição do analista "se encontra no lugar da imagem virtual", concebida numa dimensão pré-consciente dos não-ditos, suspensos nas enunciações em devir, através das formações do inconsciente e das intervenções do analista (LACAN, [1953-54], 1986, p. 186). É dita pré-consciente devido a sua propriedade de tornar consciente o inconsciente. No "Seminário 1", Lacan delimita a base fundamental da experiência analítica, assegurando, numa crítica a two bodies psichology, que a análise não se dá entre dois elementos, analista e analisante, mas a três, pois outorga à palavra sua devida consistência no papel constituinte que desempenha sobre o sujeito. Ao mesmo tempo constitutiva, a palavra também divide a subjetividade do falante em duas instâncias, o eu (moi), como função de síntese, e Eu (Je), como o pronome pessoal que designa o locutor em $1^{\text {a }}$ pessoa, isto é, o sujeito do desejo inconsciente, ou o sujeito da enunciação. Essa divisão subjetiva do falante é inaugurada por Lacan em "O estádio do espelho como formador da função do eu" 5 . O eu (com a inicial minúscula) indica o eu / ego-consciente, referente ao registro Imaginário do falante, enquanto o Eu (iniciado em maiúscula) aponta para o sujeito do inconsciente, a instância Simbólica do falante.

De acordo com o "Seminário 1", Lacan ([1954], 1986, p. 317) especifica a posição do analista como sendo a de uma "ignorantia docta". Com efeito, ele joga com o sentido de docta, cuja tradução literal corresponde a "saber", mas tomando-a como "formal", no sentido de "formadora". Tem-se então uma díade-significante, uma expressão-valise. O termo "formal" remete tanto a uma posição dentro de uma estrutura maior - a neurose de transferência no setting analítico -, como a um saber pressuposto ao analista. Como posição estrutural, ele refere-se à certa neutralidade com que convém manter-se e escutar o analisante imparcialmente; já o "saber" do analista (implícito) consiste justamente em ignorar todo saber consciente que ele acredita deter, tanto sobre o sujeito, quanto sobre o desejo, de vez que cada análise é uma experiência singular e o inconsciente é um saber que não se sabe (LACAN, [1969-70], 1992). Nesse sentido, para Lacan, o docta transforme-se em “docens", cuja tradução significa docente, em que o analista aceita sustentar-se como semblante daquele saber a ele suposto pelo analisante, figurando uma espécie de guia, que

\footnotetext{
5 Texto formulado inicialmente em 1936 e editado posteriormente em 1949. O pronome "eu" no título do artigo refere-se à instância Je, o sujeito do inconsciente, marcada nesse texto entre colchetes [eu], e não à instância moi, do eu enquanto função de síntese, cuja escrita do "eu" dá-se sem colchetes.
} 
auxilia o sujeito a encontrar o caminho singular que ele trilhará na travessia de seus fantasmas, em busca dos significantes até então recalcados que encerram as verdades alienadas de sua história em relação ao desejo do Outro (LACAN, [195354], 1986, p. 317).

No mesmo ano, em "Função e campo da fala e da linguagem em psicanálise", Lacan corrobora a tese presente no Seminário 1 , concebendo a palavra num modo mais amplo, também no sentido de discurso. Como tal, o discurso é o locus por excelência da ascese do inconsciente, donde o francês complementa que "o inconsciente do sujeito é o discurso do outro" (LACAN, [1953], 1998, p. 266), passando este outro a ser concebido, ao longo do pensamento lacaniano, tanto como o semelhante, interlocutor do sujeito, como o (grande) Outro, instância discursiva originária, que engloba os primeiros significantes maternos, o discurso parental, social e, em última instância, e por outro lado (quando em análise), a posição do analista. Vê-se aqui como esse Outro não consiste num elemento unívoco, mas ao contrário, como uma estrutura complexa, "bipolar, de toda subjetividade" (LACAN, [1948], 1998, p. 106). Ele contém, de um lado, os ideais, as aspirações, a narrativa prévia e o desejo parental dos pais sobre o infans, ao mesmo tempo que, de outro lado, a partir da figura do analista, surge como uma instância-Outra, capaz de bascular os sentidos da história do sujeito de acordo com a dimensão da alteridade suscitada por sua fala em análise, inconscientemente familiar, mas até então não reconhecida como tal.

Dois anos antes, em "Intervenção sobre a transferência”, Lacan já adiantava sua concepção de discurso como terceiro termo integrante da relação analítica. Para ele "o sujeito propriamente dito constitui-se por um discurso em que a simples presença do psicanalista introduz, antes de qualquer intervenção, a dimensão do diálogo" (LACAN, [1951], 1998, p. 215). Note-se como a "simples presença do analista", mesmo sem intervir, dá base à instauração da dimensão simbólica, dada pela interação dialógica. Ou seja, mesmo sem seu interlocutor intervir discursivamente, o falante tem a garantia de que, pelo fato de ser escutado por um ouvinte imparcial e atento, há um semelhante que ratifica, como testemunha, a implicação do sujeito com suas próprias palavras e do valor significante que ele dá a elas.

Quatro anos após o "Discurso de Roma”, em "A psicanálise e seu ensino", Lacan enfatiza mais uma vez as teses sobre a neutralidade e sobre a posição do 
analista. É como Outro, enquanto um terceiro elemento constitutivo da análise, que ele representa a presença da alteridade inconsciente, instaurada pelo uso simbólico da palavra em meio à trama discursiva através do dispositivo analítico. Segundo Lacan, é "a esse outro para além do outro que o analista dá lugar, pela neutralidade com que se faz não ser ne uter, nem um nem outro dos dois que aí estão [analista e analisante]; e, se ele se cala, é para Ihe dar a palavra [ao analisante]" (LACAN, [1957], 1998, p. 440). Ou seja, neutralidade enquanto escuta imparcial, sem intervir, e em posição de uma testemunha-simbólica-terceira, impessoal, dos relatos do analisante, e não simplesmente como um interlocutor pessoal, mero semelhante especular, desimplicado de seu desejo de analista.

Ao abordar a posição do analista em sua presença simbólica, ressalta-se alguns termos que bem a caracterizam, como: Outro, neutralidade, ignorantia docta / docens, instância terceira da linguagem / discurso e sujeito do inconsciente. A partir de agora, abordar-se-á a posição do analista no que diz respeito ao seu ser enquanto semelhante e interlocutor na interação dialógica com seu locutor, o analisando. Essa categoria engloba os aspectos subjetivos do analista de acordo com o registro Imaginário, como seus sentimentos, preconceitos, juízos, fantasias, etc.

Tal qual o analisante, o analista é também um ser constituído linguisticamente, submetido a toda sorte de consequências daí decorrentes. Ou seja, ele deseja, sente, aspira, sonha, demanda, ama, odeia, se entristece, goza, se analisa, projeta, fantasia, etc. A consequência do assujeitamento constituinte pela linguagem implica não apenas na divisão subjetiva do analista, como também no ganho de consciência sobre uma parcela de seu inconsciente e sobre como este influencia em suas vivências e relações. Quanto a isso, no "Seminário 1", Lacan adverte: "Nunca se disse que o analista não deve ter sentimentos em relação a seu paciente. Mas deve saber não apenas não ceder a eles, colocá-los no seu devido lugar, mas servir-se deles adequadamente na sua técnica" (LACAN, [1953], 1986, p. 43). Esses sentimentos, mesmo à revelia do analista, não devem por ele ser negados nem recalcados, e sim utilizados, quando necessário, em intervenções técnicas mais precisas e oportunas no manejo transferencial.

Em consonância com isso, já cinco anos antes, em "A agressividade em psicanálise", Lacan já apresenta uma primeira concepção sobre a abstenção do analista no setting. Para ele, a conduta do analista deve ser a de "oferecer ao diálogo 
um personagem tão desprovido quanto possível de características individuais; nós nos apagamos (...), evitamos qualquer manifestação de nossos gostos pessoais (...), nos despersonalizamos e tendemos a representar para o outro um ideal de impassibilidade" (LACAN, [1948], 1998, p. 109). É oportuno ressaltar o termo "representar", que pode significar apresentar de outro modo, atuar, encenar, e o termo "ideal”, referente ao que é perfeito, como no campo das ideias, isto é, real, inatingível. Esses termos, com efeito, evidenciam o quanto, no setting, o analista deve agir de acordo com a posição de um Outro, não como mero interlocutor especular, mas como "um ouvinte, e que é esse o cerne de sua função em análise", como um intérprete do discurso do analisante (LACAN, [1953], 1998, p. 249).

Concomitantemente a isso, por outro lado, situado nessa posição de uma função em análise, é um dever ético do analista deixar fora da situação transferencial qualquer resquício ou vestígio de subjetividade que possa apontar para si próprio enquanto sujeito desejante, principalmente no que concerne ao seu eu-consciente (moi), justamente aquele que deve apagar-se para dar lugar ao Es freudiano (Isso), o sujeito da interpretação, representado pela função do Outro. Seguindo essa concepção em "Função e campo da fala e da linguagem em psicanálise", Lacan traz que a "abstinência do analista, sua recusa em responder, é um elemento da realidade da análise. É nessa negatividade, na medida em que ela é pura, desvinculada de qualquer motivo particular, que reside a junção entre o simbólico e o real" (LACAN, [1953], 1998, p. 310-311). Essa "junção entre o simbólico e o real" demonstra o quanto o aspecto pessoal, imaginário do ser do analista enquanto sujeito desejante, deve abster-se de participar nas intervenções.

Em "Variantes do tratamento padrão", Lacan comenta as concepções de Sandor Ferenczi sobre a análise do analista. Para este, de acordo com Lacan, "ele [o analista] não pode, em absoluto, entregar-se ao prazer de esgotar livremente seu narcisismo e seu egoísmo na realidade em geral, mas apenas na imaginação e por breves períodos" (LACAN, [1955], 1998, p. 342). Lacan vê nisso uma "precondição que adquire valor por aparecer como aquilo que o psicanalista tem que vencer em si mesmo inicialmente" (LACAN, [1955], 1998, p. 342). E, logo em seguida, o francês questiona-se sobre quem intervém na análise e que operação torna isso possível: "(...) em todas essas instruções [para o analista], não é o eu [moi] que se apaga para dar lugar ao não-sujeito da interpretação, o Isso (Es) que fala através do analista? Aliás, 
elas só adquirem vigor pela análise pessoal do analista, e especialmente por seu fim" (LACAN, [1955], 1998, p. 343). Esgotar livremente o narcisismo e o egoísmo do analista, afirma Lacan, é o que inicialmente o analista deve vencer em si mesmo, como uma precondição à escuta clínica de outrem. E mais: quem interpreta não é um dos dois sujeitos que compõem a análise, mas um não-sujeito representado na figura do analista como Outro, como uma instância impessoal e imparcial, esvaziado de desejos enquanto ocupa a posição de uma função em análise.

Três anos depois, em "A direção do tratamento e os princípios de seu poder", Lacan relaciona os sentimentos do analista a dois significados presentes no significante 'morto': "os sentimentos do analista só tem um lugar nesse jogo: o do morto; e que, ao ressuscitá-lo, o jogo prossegue sem que se saiba quem o conduz" (LACAN, [1958], 1998, p. 595). O significante 'morto' faz menção tanto ao bridge (jogo de cartas), quanto à condição de esvaziamento subjetivo de todos os aspectos pessoais do analista mencionados até aqui. Como morto no bridge, ele sustenta-se numa condição simbólica, auxiliando o analisante a jogar as suas próprias cartas / palavras-suspensas (como o significante polifônico 'carta roubada'), escandindo os significantes de seu discurso de acordo com as manifestações do inconsciente. Já no plano imaginário da realidade consciente, o significante 'morto' assume a função de adjetivo, qualificando o ser do analista, enquanto pessoa / indivíduo, como alguém cujas características pessoais ficam apagadas, fora do "jogo", com menor importância, de modo que suas purloined letters (enquanto conflitos e fantasmas inconscientes), quando existentes, não sejam adicionadas ao percurso do analisante em análise.

Com isso, apresentou-se, além da posição simbólica do analista, como Outro do discurso inconsciente, a posição ocupada por seu ser no plano imaginário, referente a sua subjetividade pessoal, que deve esvaziar-se, abster-se de participar e operar na situação analítica. Alguns significantes que se destacam são: sentimentos do analista, ideal de impassibilidade, despersonalização, apagamento do eu, esvaziamento narcísico e posição de morto. Tendo visto os aspectos simbólico e imaginário do analista, passa-se a abordar alguns traços de sua parcela no campo do real.

Diferentemente do Imaginário e do Simbólico, o Real não tem o estatuto de registro, uma vez que este representa um meio e um espaço, um lugar (locus) passível, de alguma forma, de inscrição subjetiva. Por seu turno, o real é o que resta 
suspenso ao fim de qualquer processo ou tentativa de elaboração, simbólica ou imaginária, como algo indefinido, sobrando como um locus de fenômenos e marcas indiscerníveis, sem sentido, cuja apreensão nos outros dois registros é impossível, pois mantem-se sempre resistente à tentativa de significar-se, já que "não cessa de não se escrever". (CHEMAMA, 1995, p. 184). Em "A direção da cura" Lacan postula que o analista está tão envolvido na análise quanto o analisante, pois paga com suas "palavras" no registro simbólico, com seu "juízo mais íntimo" no imaginário e com sua "pessoa como suporte dos fenômenos transferenciais" no campo do real (LACAN, [1958], 1998, p. 593).

Já em o "Seminário 10 - A angústia", o que aponta a marca e a proximidade com o real é a angústia, o afeto irrefutável por excelência, responsável pela passagem do gozo ao desejo (LACAN, [1962-1963], 2005). Assim, quando a angústia toca o analista no real de uma sessão, algo da situação transferencial pode estar apontando para um aspecto do seu inconsciente ainda não mobilizado, advertido ou elaborado, o que aponta para a importância fundamental das supervisões e da análise do analista (a didática), onde ele tem a oportunidade de analisar suas diversas instâncias psíquicas, discernindo-as mais claramente e podendo apropriar-se melhor do $E s$, o Isso, enquanto Je, Eu em $1^{\text {a }}$ pessoa. O aforismo lacaniano "penso onde não sou, logo sou onde não penso" expressa bem a divisão subjetiva de todo falante, inclusive a do analista, ao passo que ele o é apenas não pensando nisso ("no Isso" da cena analítica), enquanto escorrega desse lugar ao pensar nele, quando cai na posição de semelhante do analisante como sua imagem especular (o a' no esquema L) (LACAN, [1957], 1998, p. 521).

\section{O ‘Esquema L’ do ReConHeCIMENTo INTERSubJetivo}

Após as premissas iniciais dadas no "Discurso de Roma", Lacan segue desenvolvendo o tema da intersubjetividade no ano seguinte, através do "Seminário 2

- O eu na teoria de Freud e na técnica da psicanálise" e do "Seminário sobre 'A carta roubada"', de acordo com o esquema do reconhecimento intersubjetivo, esquema $Z$, ou ainda, como é mais conhecido, o esquema L. Em "O seminário sobre 'A carta roubada'”, o esquema $L$ é apresentado como um quadrípode, composto pelo eu (a), o outro (a'), o A (grande Outro) e S (sujeito do inconsciente) (LACAN, [1955], 1998, p. 
58). Na análise desse conto do escritor norte-americano E. Alan Poe, o psicanalista demonstra como os sujeitos estão constantemente trocando suas posições simbólicas uns com os outros em suas interrelações, e como isso é determinado pelo inconsciente, à revelia da percepção e das intenções conscientes dos sujeitos. $O$ mesmo ocorre com suas instâncias psíquicas, posto seu assujeitamento à cadeia significante regida pelas leis inconscientes, que procuram ser visualizadas aqui através do desdobramento subjetivo do analista de acordo com o esquema L.

Em “O Seminário 2", Lacan explica como cada termo se relaciona, a princípio, dois a dois, sendo a - a' (o eu e o outro, seu semelhante) a linha do registro Imaginário, do discurso consciente, e A - S (o Outro e o sujeito do inconsciente) o registro Simbólico, compreendendo os enunciados e enunciações e os ditos e os não-ditos, de acordo com a figura 1, abaixo. Nesse Seminário, Lacan caracteriza o segmento a - a' como o plano especular (de eu a eu), dando a ele o estatuto de uma "falsa realidade", e o denomina como "muro da linguagem", pois essa dimensão falsa da realidade especular obstaculiza, no plano significante consciente, dos enunciados, do discurso e de sua narrativa, o acesso pleno do sujeito aos significantes recalcados de sua história pregressa ainda não percorrida, impedindo, por vezes, a possibilidade de encontros com novas significações e reelaborações (LACAN, [1954-55], 1985, p. 307).

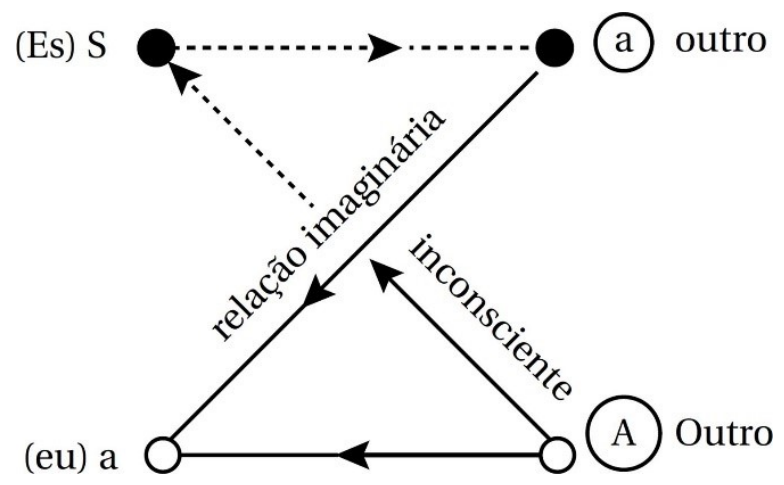

Figura. 1

Mas os quatro termos do esquema $L$ não se relacionam apenas dois a dois. Ao percorrer a escrita desse percurso em forma de um " $Z$ retorcido" do esquema $L$, o Outro (A) emite a mensagem tanto para o eu (a), como para seu registro inconsciente (Es). Este "Isso" - o sujeito do inconsciente - endereça sua mensagem para o interlocutor a', enquanto seu semelhante. Por sua vez, este interlocutor (a'), reenvia a mensagem de volta ao eu-locutor (a), que recebe a face imaginária da mensagem através dos enunciados, enquanto a dimensão inconsciente dá-se a nível da 
enunciação e dos não-ditos, pois o diálogo entre os interlocutores é distorcido, clivado e barrado pelo muro da linguagem. Surge daí outro aforismo lacaniano: o inconsciente é a mensagem invertida que retorna do Outro para o sujeito, sendo o trabalho analítico o de auxiliá-lo a transcrever sua mensagem / história, que, por ser proveniente do Outro enquanto instância inconsciente, transparece como uma meia-verdade, um enigma a ser interpretado, desvendado. Ou ainda, conforme J. Dor: "o emissor recebe do receptor sua própria mensagem invertida" (1989, p. 158).

\section{As “Lentes” dA Linguística NA LeituRA do Esquema L}

Sendo a proposta do presente trabalho desdobrar as posições do analista de acordo com o esquema $L$ no período de prevalência do registro Simbólico, explanarse-á uma prévia das bases teóricas de Lacan naquele período, a saber: o estruturalismo e a linguística. As bases estruturalistas provém de C. Lévi-Strauss (2007), segundo o qual as relações inter-humanas se realizam de acordo com o sistema de parentesco familiar estudado por ele em diversas culturas, o que fez com que esse teórico caracterizasse esse regime como universal, válido para todos os sujeitos e sociedades. Foi a partir do trabalho de Lévi-Strauss que Lacan releu a obra freudiana, atualizando a leitura da noção de sistema (também presente em Freud) por estrutura (que Freud não utilizava), principalmente no que concerne à horda primeva, ao mito edipiano, à interpretação dos sonhos e à dissecação da personalidade psíquica.

Já no campo da linguagem, Lacan parte do linguista genebrino F. de Saussure ([1916] 2008, p. 23), que abordava a língua enquanto um "sistema de signos", seguindo-a a partir da linguística enunciativa, desenvolvida pelo francês É. Benveniste. Este, contemporâneo de Lacan, passou a conceber a linguística também como uma teoria estruturalista, isto é, que engloba não apenas elementos dentro de um único sistema isolado, mas sim, diversos sistemas relacionados entre si, de acordo com normas específicas, formando, então, as estruturas. A partir disso, considerando as instâncias psíquicas da $2^{\mathrm{a}}$ tópica freudiana eu, isso e supereu (FREUD, [1923], 1996) ou as instâncias lacanianas eu (moi) e Eu (Je), como elementos constitutivos do sistema psíquico em Freud ou subjetivo para Lacan, é possível considerar, agora numa abrangência mais ampla, os sistemas psíquico / subjetivo dos falantes como 
outros elementos (maiores e mais complexos que as instâncias) como sendo constituintes da relação analítica entre analista e analisante. Nesse sentido, esses sistemas podem ser circunscritos e concebidos de acordo com o esquema L, como uma estrutura / dispositivo que comporta, relaciona e reorganiza esses sujeitos de acordo com a dinâmica transferencial.

Além de Benveniste, Lacan busca outros conceitos do linguista russo $\mathrm{R}$. Jakobson (2007), também estruturalista, como os de código, mensagem, remetente, destinatário, metáfora, metonímia e shifter (ou embrayeurs, em francês). Priorizando o conceito de shifter no presente trabalho, esta noção corresponde a termos que articulam certas categorias linguísticas, como a relação entre pronomes pessoais e seus derivados e a variação das pessoas e tempos verbais nos enunciados. Assim, os shifters podem ser aqui entendidos como articuladores, que promovem a relação entre certos elementos da língua, ao mesmo tempo que são capazes de deslocar os termos dessas relações, realocando-os em posições diferentes das anteriores e ressignificando o interior das estruturas das quais fazem parte. Com efeito, o interesse pela noção de shifter aqui é mister, já que a proposta é utilizar o próprio esquema $L$ como um shifter, ou seja, como um dispositivo linguístico / metapsicológico que proporciona a interação entre remetente e destinatário (analista e analisante, em psicanálise), sendo capaz de articular, no discurso, o registro Simbólico, dos não-ditos e das enunciações inconscientes, ao plano Imaginário da interlocução consciente, de eu a eu, isto é, do sujeito com o outro.

Também na linguística enunciativa de Benveniste ([1958], 1991), Lacan utilizase de uma noção correlata a de shifter: a dêixis ou dêiticos. Essa noção é a responsável por indicar a presença da subjetividade na linguagem, dada principalmente pelos pronomes pessoais, possessivos, demonstrativos e os advérbios de tempo e espaço (BENVENISTE, [1956], 1991, p. 279). É certo que na linguística Benveniste não analisa nem investiga as manifestações do inconsciente na linguagem, mas Lacan serve-se da teoria e dos conceitos do linguista para fundamentar cientificamente os estudos e investigações da psicanálise. Outras noções fundamentais que Lacan extrai de Benveniste ([1970], 2006) é o par enunciado e enunciação. Para o linguista, a enunciação corresponde ao uso que o indivíduo faz da linguagem verbal nos momentos em que se coloca como falante, isto é, ao utilizar "a capacidade do locutor para se propor como sujeito" (BENVENISTE, [1958], 1991, 
p. 286). Já o(s) enunciado(s) corresponde(m) a todos os ditos, às enunciações, enfim, tudo aquilo que é ou foi pronunciado pelo falante e que fica registrado através dos enunciados como produto de sua fala / discurso.

Enquanto isso, para Lacan, a noção de enunciado mantém praticamente as mesmas particularidades dadas por Benveniste, mas o conteúdo, o significado ou o sentido da enunciação não é equivalente ao conteúdo do enunciado. Assim como os dêiticos apontam a presença da subjetividade na linguagem, a enunciação aponta para as formações do inconsciente na fala / discurso numa análise, podendo ser proferida tanto pelo analista quanto pelo analisante. Isso decorre do fato de que a mensagem inconsciente provém da posição do Outro enquanto instância terceira da relação transferencial, de tal modo que a enunciação não representa a voz nem de um, nem de outro, mas sim, presentifica o Isso, o Sujeito do inconsciente, através da voz de um deles enquanto materialidade linguística, cuja função é ser o intérprete da história narrada pelo analisante (LACAN, [1960], 1998).

\section{O Desdobramento Subjetivo do Analista no Esquema L}

Em "A coisa freudiana", Lacan deslinda mais detidamente os efeitos do atravessamento linguístico / simbólico sobre o falante. Ele retoma a divisão subjetiva a partir do esquema $L$, chegando a dizer que a análise não se compõe de três elementos, como visto anteriormente: analista, analisante e o Outro; mas de quatro termos. Nesse mapeamento, ele situa tanto as instâncias do analisante quanto as do analista nas duas dimensões do esquema $L$, a simbólica $(S-A)$ e a imaginária $(a-$ a'), clivando-os nos estratos consciente e inconsciente. Obtém-se, então, como resultado dessa clivagem, o analisante dividido entre eu (a) e Es (S), e o analista, como outro (a') e A (Outro), respectivamente nos registros Imaginário e Simbólico.

Na leitura dessas instâncias em cada uma dessas posições pode-se dizer que o eu do analisante (a) está para o eu do analista (a') no plano imaginário / consciente, assim como o Es do analisante, o sujeito do inconsciente (ou Je), está para a figura do analista situado na posição de Outro na dimensão simbólica / inconsciente. Contudo, é justamente na posição de a' do eixo imaginário a - a' que o analista deve apagar-se, de modo que seus atributos pessoais não participem do jogo analítico, o que restitui a tríade analista, analisante e Outro. Assim, para Lacan, o analista 
“intervém concretamente na dialética da análise se fazendo de morto, cadaverizando sua posição (...), seja por seu silêncio, ali onde ele é Outro (...), seja anulando sua própria resistência, ali onde ele é outro (...). Em ambos os casos e sob as respectivas incidências do simbólico e do imaginário, ele presentifica a morte" (LACAN, [1955], 1998, p. 431).

É nesse ponto, onde se conectam a dimensão simbólica e a imaginária, que o presente trabalho propõe utilizar o esquema $L$ no sentido de um shifter, como um dispositivo de análise metapsicológica. O ponto central desse shifter, onde se tocam Simbólico e Imaginário, é também a posição a partir da qual o esquema é capaz de bascular, como os movimentos de uma gangorra, os dois registros entre si, situando a interação entre os falantes ora no plano do discurso corrente e ora apontando para o surgimento da alteridade na linguagem, irrompida nas formações do inconsciente do analisante ou como efeito das interpretações do analista de acordo com a abertura do inconsciente na livre associação da cadeia enunciativa (LACAN, [1960], 1998).

Nesses momentos de apontamento da presença de questões inconscientes, quem fala é o Isso (Es), enquanto sujeito do inconsciente, independentemente de qual dos dois enunciadores tenha dado voz a ele. No entanto, procurando visualizar melhor como se apresenta dividida a posição do analista através do esquema $L$, entende-se que é possível considerá-la a partir de duas situações. A primeira, em que predomina a narrativa do analisante, mesmo com o analista intervindo em alguns pontos, sem, contudo, irromper nessas interações a presença de elementos inconscientes, plano, então, em que ambos dialogam no âmbito consciente do registro Imaginário. A segunda situação pode ser concebida quando se destaca, tanto no discurso do analisante como nas intervenções do analista, a manifestação de alguma formação do inconsciente. Neste segundo caso, propõe-se levar em conta, ainda, uma última seção, que se estabelece, por um lado, de acordo com a intervenção do analista e, por outro, de acordo com a fala do analisante, seções estas, ambas perpassadas pela dimensão simbólica da alteridade inconsciente.

Retomando-se o foco do texto de volta à posição do analista, que se a observe de acordo com a primeira situação, do discurso consciente no plano imaginário. Nessa cena, onde não surgem indicativos de elementos inconscientes, o que sustenta o semblante do Outro, enquanto lugar capaz de trazer à tona a dimensão da alteridade para o analisante, é a atenção flutuante e o silêncio mantido pela abstinência do 
analista (FREUD, [1912], 1996) como testemunha da história narrada pelo sujeito em sua condição de verdade plena. Nesta situação, então, o Outro dá suporte à dimensão inconsciente para o analisante, mas apenas enquanto o analista guarda silêncio, sem se manifestar, de um modo ou de outro. Por outro lado, quando o analista dirige alguma indagação ao analisante, quando realiza alguma intervenção mais genérica (procurando esclarecer o conteúdo de algum segmento de fala, por exemplo), ou, mesmo quando lança alguma intervenção ao analisante com a expectativa de que ela seja recebida como uma interpretação ou como uma pontuação que o analista julga poder expressar ou sinalizar algo do inconsciente, mas que o analisante não a reconhece como tal, o esquema $L$ bascula a posição do analista enquanto se mantem em silêncio na posição A do esquema (como Outro), para a posição de a', o (pequeno) outro, tornando-o um interlocutor semelhante ao analisante, ambas posições à direita no esquema L. Com isso, vê-se que, quando as intervenções do analista não tocam ou produzem algum efeito de ressignificação do discurso ou de suspensão das certezas do analisante, o que poderia oportunizar, mesmo nachträglichkeit (a posteriori), a busca ou a aproximação de algum conteúdo inconsciente, o analista passa da posição de Outro à condição de outro, mero interlocutor especular, deslizando da dimensão simbólica (enquanto ouvinte silencioso) para o plano ilusório das miragens e dos enunciados imaginários, barrado que se encontra pelo muro da linguagem.

Passando agora à segunda situação, em que ocorre o surgimento de elementos indicativos da alteridade, tanto a voz do analista quanto a voz do analisante podem dar suporte às manifestações do inconsciente, materializando-as num corpo enunciativo (discurso), cujo efeito de laço social corrobora a instauração do "sujeitosuposto-saber" (SSS) e do enlace transferencial (Lacan, [1967], 2003). Seccionando agora esta última situação primeiramente pela parte do analista, quando suas interpretações ou demais tipos de intervenções fisgam ou atingem a presença de algo inconsciente na fala do analisante, pode-se dizer que a voz impessoal do Isso ganha vida através da enunciação do analista, quando a pontuação deste aponta as manifestações do inconsciente e delimita seu fechamento na cadeia significante (LACAN, [1964], 1979). Enquanto sujeito desejante, então, o analista apaga seu ser na posição a', como interlocutor direto e pessoal do analisante, ao mesmo tempo em que, diferentemente da primeira situação abordada mais acima, mesmo quando se 
manifesta como falante, ele mantem-se na posição de $A$, não mais como outro especular (como em a'), mas agora como Es, um Outro impessoal, destituído de propriedades subjetivas. Ou, de acordo com A. de Souza (1988), pode-se dizer que, quando o dito do analista se realiza como interpretação, é porque seu enunciado toca na enunciação do analisante. Seccionando agora esta segunda situação, a voz impessoal do Es acede, enfim, pelo lado do analisante, doravante não mais como sujeito inconsciente, impessoal, mas sim como Je, isto é, como ser desejante que se constitui, ou melhor, que constitui a Si próprio, não inconscientemente, e sim desperto, em $1^{a}$ pessoa, como Sujeito do enunciado, em sua própria enunciação.

Neste caso, quando a escuta do analisante começa a se tornar naturalmente perceptível à presença de elementos que apontem, ou possam apontar, para questões até então não percebidas por ele sem o auxílio das intervenções do analista, essa percepção indica que ele não fala mais de uma posição discursiva paciente ou histérica ${ }^{6}$, mas sim que, identificado que está nesse momento da análise com o semblante do analista na condição de Outro $^{7}$, é ele agora, o analisante, que ocupa a posição do analista como agente enunciativo, de modo que seu discurso se instaura correlativamente ao discurso do analista. Com razão, para Lacan ([1958], 1998) é isso que indica que o analista vinha desempenhando adequadamente sua função na direção da cura ao dirigir o tratamento e não o analisante, atuando simbolicamente não como a ou a' (o eu e sua imagem especular), mas sim como o objeto a, causa do desejo (LACAN, [1962-63], 2005) para o analisante trilhar sua análise de acordo com um desejo singular, o desejo do analista, de conduzir as análises até sua conclusão (LACAN, [1964], 1979), resultado de uma análise que se configura, ao fim, como didática, tanto para o analista que já concluiu sua análise, quanto para o analisante que, ao concluir a sua, advém como analista.

A identificação do analisante ao analista pode ser ilustrada também de acordo com os dois eixos do esquema L. Num primeiro tempo, essa relação de identificação entre os parceiros da relação analítica é mantida no plano imaginário a - a', do eu ao outro, na dimensão especular. Designado por Freud ([1913], 1996) como

\footnotetext{
${ }^{6}$ Segundo os matemas no "Seminário 17, O avesso da psicanálise" (1969-1970), o histérico é um dos quatro discursos da teoria lacaniana, juntamente com o discurso do mestre, o analítico e o universitário. ${ }^{7}$ Em "Observações sobre o relatório de Daniel Lagache" (1960) e em "O seminário 8, A transferência" (1960-1961), Lacan explana, em pormenores, a identificação do analisante com o analista em determinado período da análise, antes da queda do Outro como objeto a, que causa o desejo no e para o analisante, indicando a proximidade com o término da análise.
} 
tratamento de ensaio, esse período, bem inicial em algumas análises, foi também nomeado por Lacan de entrevistas preliminares (Quinet, 1993), enquanto o sujeito não concebe o analista como Outro, ou seja, enquanto não atribui um certo tipo de saber inconsciente ao analista (sobre si e seu desejo), antes de tomá-lo como o sujeitosuposto-saber, saber do qual o sujeito se acredita despossuído. A partir dos primeiros efeitos simbólicos das intervenções do analista, que apontam para a clivagem subjetiva do falante e para os sintomas enquanto retornos do recalcado, se anuncia a passagem do momento inicial da análise para um segundo tempo, marcado, de acordo com Freud ([1912], 1996), pela associação livre do analisante e pela consolidação gradual do vínculo transferencial: a análise propriamente dita. A partir desse segundo tempo da análise, então, a relação entre os interlocutores pode agora ser concebida em meio ao eixo simbólico A - S, enlaçada entre o Outro, semblante do inconsciente, e o Je, sujeito de desejos barrado pelo muro da linguagem.

Como já dito, o Real não é mencionado em meio ao esquema $L$, até porque, para que as identificações possam se instaurar entre os sujeitos, é necessária a existência de certos traços subjetivos, os quais só são passíveis de inscrição através dos registros Simbólico e Imaginário. Além do mais, o Real funda-se num tempo mítico originário, anterior ao surgimento do aparelho psíquico e, portanto, na ausência de um espaço de memória, sem o qual não há meios de registros possíveis de qualquer impressão e armazenamento subjetivo, quando se instaura, então, o recalcamento primário (FREUD, [1915], 1996). Será somente a posteriori, quando a tensão pelo investimento pulsional disperso se torna excessiva, que a angústia, como resultado desse excesso de tensão, produz o recalcamento secundário ou propriamente dito (FREUD, [1933], 1996). Este, por sua vez, reúne e contém o excedente de energia dispersa num organismo vivo (o corpo humano) ainda desprovido de um locus representacional. Isso estabelece a clivagem dessa tensão num núcleo tornado a sede energética pulsional, o recalque originário, ou o real como o núcleo para sempre intraduzível das origens psíquicas, e separando esse núcleo, através do recalcamento secundário, do restante da parte representacional, que, a partir de então, fornece um espaço aos âmbitos pré-consciente e inconsciente do psiquismo, dando base à formação das instâncias lacanianas do moi e do Je (LACAN, [1949], 1998).

A partir da instauração do recalcamento propriamente dito funda-se, então, o início do aparelho psíquico, onde as catexias oriundas do recalcamento primário são 
capazes de se associarem, agora, aos Vorstellungsrepräzentanz, traduzidos por Lacan ([1964], 1979) como os representantes das representações inconscientes, formando assim as pulsões - um dos conceitos fundamentais da psicanálise - como uma noção fronteiriça e complexa, situada por Freud ([1915], 1996) "entre o somático e o psíquico", pois enlaça uma representação mental a uma catexia, um quantum de afeto, provendo-Ihe de uma força para o movimento que veicula, em si, um conteúdo ideativo. Já a partir de "A direção da cura", Lacan inicia a referenciar e relacionar o âmbito do Real à situação analítica, porém não submetido nem associado a possibilidades representacionais, e sim através da angústia, o afeto acometido ao corpo - o terceiro aspecto, não representado no esquema $L$, com o qual o analista paga nas análises - com o qual o psiquismo não se engana nem consegue se deixar iludir, já que se manifesta como gozo incessante não vinculado a nenhum dos dois outros registros da psiquê.

\section{CONSIDERAÇÕES FINAIS}

O presente trabalho buscou investigar como visualizar a divisão subjetiva do psicanalista nos registros lacanianos do Simbólico e do Imaginário em meio a uma análise. Para isso, relacionou o esquema $L$ à noção linguística de shifter, como um dispositivo de análise metapsicológica, a fim de articular aqueles dois registros às instâncias Je e moi, ambas constituintes da noção de sujeito divido, ou sujeito do desejo inconsciente, na teoria lacaniana do inconsciente estruturado como uma linguagem. Com efeito, viu-se o quanto essas instâncias estão imbricadas entre si e imiscuídas em meio aos planos simbólico e imaginário. Ao longo de toda a fala, como em cada palavra pronunciada, estão presentes no falante o eu, o "moi consciente", e o Je, enquanto "isso inconsciente".

Ao investigar o desdobramento subjetivo do analista, foi possível visualizar que, no registro Imaginário, o ser do analista situa-se como um interlocutor dividido, à imagem especular do analisante, resguardando deste, porém, qualquer traço de subjetividade em si, enquanto no Simbólico, ele subtrai-se da cena enquanto sujeito desejante, cedendo seu lugar à posição de Outro, como intérprete dos fenômenos inconscientes. Mesmo assim, em seu ofício ético, o analista leva e entrega, em cada análise, suas palavras, seus juízos e sua pessoa. Por isso, tanto no plano imaginário quanto no simbólico, o analista deve figurar a posição da morte, fazendo representar, 
para o analisante, a separação e a queda do desejo do Outro enquanto discurso parental alienante, e apontando pistas que conduzam o percurso do analisante para a conclusão de sua análise.

Depreendeu-se dessa investigação, contudo, que, tanto os registros Simbólico e Imaginário, e, por conseguinte, as instâncias moi e Je assentam-se sobre um vértice comum, o corpo do analista, circunscrito, então, como a base do campo do Real no que concerne ao debate acerca do presente estudo, de vez que cada sujeito é o resultado da operação estabelecida de acordo com o impacto do discurso do Outro sobre o circuito pulsional que perpassa e erogeneiza o seu corpo. Excluído das teorizações lacanianas acerca do esquema $L$ no período de prevalência do Simbólico, o campo do Real faz-se mister na compreensão metapsicológica do dispositivo analítico e dos fenômenos transferenciais ali produzidos e analisados, pois é um dos três anéis sem o qual a trilogia SIR não comporta a constituição e o desenvolvimento subjetivo do falante. Com isso, é através não apenas de sua condição estrutural, como também do seu corpo, que o analista é capaz de metabolizar e "decodificar" os afetos transferenciais e contratransferenciais desencadeados e vivenciados nas experiências com cada analisante, devolvendo a estes seus significantes "destorcidos" do e pelo Isso.

A compreensão metapsicológica desses fenômenos e a metabolização dos afetos despertados e manejados transferencialmente aponta, sobretudo, para a importância de uma conclusão bem elaborada da análise didática do analista. Quando assim se conclui, ela dá provas tanto da transmissão de um saber inconsciente, com o qual o analisante - e futuro analista - se implica eticamente, quanto da retificação estrutural que viabiliza sua ascensão, primeiramente à posição de Outro, para, posteriormente, desfalecer na condição de resto, como objeto a, causa do desejo, mobilizado e instituído pelo desejo do psicanalista. Pois é ao longo de uma análise, pelos meandros dos atos-falhos, das interpretações e das construções em análise, que o sujeito tem a oportunidade de tornar consciente esse 'Isso' que o habita e o constitui, promovendo assim o encontro, cada vez mais próximo, de acordo com o clássico "Wo Es war, soll Ich werden", entre o moi e Je, isso e Eu.

8“Onde está o isso, Eu devo advir”. (“A coisa freudiana” [1955], In: Escritos, 1998). 


\section{REFERÊNCIAS}

BENVENISTE, É. (1956). A natureza dos pronomes. In: Problemas de linguística geral I. $3^{\text {a }}$ ed. Pontes: São Paulo, 1991.

(1958). Da subjetividade na linguagem. In: Problemas de linguística geral I. $3^{\text {a }}$ ed. Pontes: São Paulo, 1991.

. (1970). O aparelho formal da enunciação. In: Problemas de linguística geral II. $2^{\mathrm{a}}$ ed. Pontes: São Paulo, 2006.

CHEMAMA, R. Dicionário de psicanálise Larousse. Artmed: Porto Alegre, 1995.

DOR, J. Introdução à leitura de Lacan: o inconsciente estruturado como uma linguagem. Artmed: Porto Alegre, 1989.

FREUD, S. (1900). A interpretação dos sonhos. In: Edição standard brasileira das obras completas de Sigmund Freud. Vol. II. Rio de Janeiro: Imago, 1996.

. (1912). Recomendações aos médicos que exercem a psicanálise. In: Edição

standard brasileira das obras completas de Sigmund Freud. Vol. XII. Rio de Janeiro: Imago, 1996.

(1913). Sobre o início do tratamento. In: Edição standard brasileira das obras completas de Sigmund Freud. Vol. XII. Rio de Janeiro: Imago, 1996.

. (1915). Os instintos e suas vicissitudes. In: Edição standard brasileira das obras completas de Sigmund Freud. Vol. XIV. Rio de Janeiro: Imago, 1996.

. (1915). Repressão. In: Edição standard brasileira das obras completas de Sigmund Freud. Vol. XIV. Rio de Janeiro: Imago, 1996.

. (1923). O ego e o id. In: Edição standard brasileira das obras completas de Sigmund Freud. Vol. XIX. $2^{\mathrm{a}}$ ed. Rio de Janeiro: Imago, 1996.

. (1933). Conferência XXXII - Ansiedade e vida instintual. In: Edição standard brasileira das obras completas de Sigmund Freud. Vol. XIX. 2ª ed. Rio de Janeiro: Imago, 1996.

. (1937). Análise terminável e interminável. In: Edição standard brasileira das obras completas de Sigmund Freud. Vol. XXIII. 2a ed. Rio de Janeiro: Imago, 1996.

. (1937). Construções em análise. In: Edição standard brasileira das obras completas de Sigmund Freud. Vol. XXIII. $2^{\mathrm{a}}$ ed. Rio de Janeiro: Imago, 1996.

HOLANDA, A. B. Dicio: Dicionário Online de Português. Disponível em: https://www.dicio.com.br/

JAKOBSON, R. (1958). Os articuladores, as categorias verbais e o verbo russo. (Versão mimeografada). 
. Linguística e comunicação. São Paulo: Cultrix. 2007.

KAUFMANN, P. Dicionário enciclopédico de psicanálise: o legado de Freud a Lacan. Rio de Janeiro: Zahar, 1996.

LACAN, J. (1936). Para-além do "Princípio de realidade”. In: Escritos. Rio de Janeiro: Zahar, 1998.

. (1948). A agressividade em psicanálise. In: Escritos. Rio de Janeiro: Zahar, 1998.

. (1949). O estádio do espelho como formador da função do eu. In: Escritos. Rio de Janeiro: Zahar, 1998.

. (1951). Intervenção sobre a transferência. In: Escritos. Rio de Janeiro: Zahar, 1998.

. (1953). Função e campo da fala e da linguagem em psicanálise. In: Escritos. Rio de Janeiro: Zahar, 1998.

. (1953-1954). O Seminário, livro 1: Os escritos técnicos de Freud. Rio de Janeiro: Zahar, 1986.

. (1954-1955). O Seminário, livro 2: O eu na teoria e na técnica de Freud. Rio de Janeiro: Zahar, 1985.

1998.

. (1955). O Seminário sobre ‘A carta roubada'. In: Escritos. Rio de Janeiro: Zahar,

(1955). Variantes do tratamento padrão. In: Escritos. Rio de Janeiro: Zahar, 1998.

(1995). A coisa freudiana. In: Escritos. Rio de Janeiro: Zahar, 1998.

. (1957). A psicanálise e seu ensino. In: Escritos. Rio de Janeiro: Zahar, 1998.

. (1957). A instância da letra no inconsciente ou a razão desde Freud. In: Escritos. Rio de Janeiro: Zahar, 1998.

Zahar, 1999.

(1957-1958). O Seminário, livro 5: As formações do inconsciente. Rio de Janeiro:

. (1958). A direção do tratamento e os princípios de seu poder. In: Escritos. Rio de Janeiro: Zahar, 1998.

. (1960). Subversão do sujeito e dialética do desejo no inconsciente freudiano. In:

Escritos. Rio de Janeiro: Zahar, 1998.

. (1960). Posição do inconsciente. In: Escritos. Rio de Janeiro: Zahar, 1998.

. (1960-1961). O Seminário, livro 8: A transferência. Rio de Janeiro: Zahar, 1992. 
. (1962-1963). O Seminário, livro 10: A angústia. Rio de Janeiro: Zahar, 2005.

. (1964). O Seminário, livro 11: Os conceitos fundamentais da psicanálise. Rio de Janeiro: Zahar, 1979.

. (1967). Proposição de 9 de outubro de 1967 sobre o psicanalista da Escola. In: Outros Escritos. Rio de Janeiro: Zahar, 2003. 1992.

. (1969-1970). O Seminário, livro 17: O avesso da psicanálise. Rio de Janeiro: Zahar,

LÉVI-STRAUSS. Antropologia estrutural. Rio de Janeiro: Tempo brasileiro, 2007.

QUINET, A. As 4 + 1 condições da análise. Rio de Janeiro: Zahar, 1993.

SAUSSURE, F. (1916). Curso de linguística geral. São Paulo: Cultrix, 2008.

SOUZA, A. Transferência e interpretação. Porto Alegre: Artmed, 1988. 


\title{
The Position of the Psychoanalyst AND hIS UNFOLdING OF THE SUBJECTIVE IN THE SCHEME L
}

\begin{abstract}
The present study aims to investigate how to give yourself a split from the subjective to the analyst, in the records of lacanians in the symbolic and the imaginary. To do this, we are going to use the schema $L$ as for a while, that is to say, a review metapsychological, to be the psychic instances moi and Je of the analyst, pursuant to, on the one hand, the plan is mindful of the interaction of the concrete between the actors, which is influenced by the other, and the dimension of the unconscious is produced by the use of the language among them. It is in the real field, but it is located at the apex between the imaginary and the symbolic, in the body of the analyst, by which he paid for with his own person, "metabolizing" total transferences. As a outcome, it can be seen that the extracts from the symbolic, and the imaginary of the analyst are intimately entwined, and you can see it in the silence of the analyst, as well as by their speeches, when their enunciation act upon the property of interpretation.
\end{abstract}

KEYWORDS: The position of the analyst. Schema L. Shifter. Enunciation. Subject to the split. 


\section{La Position du Psychanalyste et son DéRoulement de LA SUBJECTIVITÉ DANS LE SCHÉMA L}

\section{RÉSUMÉ}

Le présent travail se propose d'examiner comment se déroule la subjectif de l'analyste dans les registres lacaniens du symbolique et de l'imaginaire. Pour cela, le schéma L servira comme un shifter, c'est-à-dire, un dispositif d'analyse métapsychologique, permettant de situer les instances du moi et du je psychique de l'analyste, selon le plan conscient, par un côte, de l'interaction concrète entre les interlocuteurs, qui sont traversés, par l'autre côte, par la dimension inconsciente produite par l'utilisation du langage entre eux. C'est cependant dans le champs du réel qui se situe le vertice entre l'imaginaire et le symbolique, dans le corps de l'analyste, par lequel il paye avec sa personne, en "métabolisant" le transfert. En conclusion, les strates symbolique et imaginaire de l'analyste sont intimement imbriquées et visualisées à la fois par le silence de l'analyste et par ses interventions, lorsque son énoncé agit avec des propriétés interprétatives.

MotS-CLÉs: Position d'Analyste. Schéma L. Shifter. Énonciation. Sujet Divisé. 
RECEBIDO EM 05/09/2020

ACEITO EM 30/11/2020

C 2020 Psicanálise \& Barroco em revista

http://www.seer.unirio.br/index.php/psicanalise-barroco/index

revista@psicanaliseebarroco.pro.br

Programa de Pós-Graduação em Memória Social — UNIRIO

Memória, Subjetividade e Criação

www.memoriasocial.pro.br/proposta-area.php 